\title{
Morphological risk factors associated with dislocation after bipolar hemiarthroplasty of the hip in patients with femoral neck fractures-a nested case-control study
}

\author{
Yueqi Zhang ${ }^{1+}$, Zhenjun Yao ${ }^{1+}$, Peng Shi ${ }^{2 \dagger}$, Chenzhong Wang ${ }^{1}$, Jinyu Liu', Yi Yang ${ }^{1 *}$ and Chi Zhang ${ }^{1 *}$
}

\begin{abstract}
Background: The relationship between preoperative hip measurements and dislocation after bipolar hemiarthroplasty is presently unclear. In the current study, we investigated the morphological risk factors associated with dislocation after bipolar hemiarthroplasty of the hip in patients with femoral neck fractures.

Methods: Between January 2011 and June 2017, a nested case-control design study was used to analyze the risk factors for dislocation in 348 patients who had undergone bipolar hemiarthroplasty because of femoral neck fractures. Twelve patients underwent at least one dislocation postoperatively. Sixty patients without dislocation were selected as controls matched in terms of time of surgery, age, and sex, at a ratio of 1:5. Patient acetabular measurements were compared between the dislocation group and the control group, including the center-edge angle, abduction angle, acetabular width and depth, depth-to-width ratio, femoral neck offset, leg length discrepancy, and femoral head coverage ratio. A multivariate logistic regression model was used to evaluate the morphological risk factors of dislocation.
\end{abstract}

Results: Postoperatively, the incidence of dislocation was 3.4\%. A smaller center-edge angle was found to be a risk factor associated with dislocation after bipolar hemiarthroplasty of the hip. Patients with small acetabular depth and a small acetabular depth-width ratio were prone to dislocation. Patients with a center-edge angle of $\leq 45.4^{\circ}$ or an acetabular depth of $\leq 19.12 \mathrm{~mm}$ were more likely to suffer dislocation.

Conclusions: Careful preoperative measurements before bipolar hemiarthroplasty of the hip are important. Surgical intervention for femoral neck fracture patients with a shallow acetabulum should be carefully planned and total hip arthroplasty should be considered when necessary.

Keywords: Hemiarthroplasty, Dislocation, Acetabular depth, Center-edge angle

\section{Background}

Femoral neck fracture is one of the most common orthopedic fractures in the elderly, which directly influences their mobility and causes clinical complications leading to a higher mortality rate $[1,2]$. With the aging population, it is predicted that the total number of femoral neck fractures will rise to 6.26 million per year in

\footnotetext{
* Correspondence: yang.yi@zs-hospital.sh.cn; chizhangg@hotmail.com

†Yueqi Zhang, Zhenjun Yao, Peng Shi are co-first authors

${ }^{1}$ Department of Orthopedic Surgery, Zhongshan Hospital, Fudan University,

180 Fenglin Road, Shanghai 200032, China

Full list of author information is available at the end of the article
}

2050 [3]. Surgical treatment options for femoral neck fractures include internal fixation, hemiarthroplasty or total hip arthroplasty (THA) [4]. A study by Haidukewych et al. showed that bipolar hemiarthroplasty was associated with excellent component survivorship in elderly patients with displaced femoral neck fractures [5]. A bipolar hemiarthroplasty has become the accepted treatment for elderly displaced femoral neck fracture patients. Compared with THA, bipolar hemiarthroplasty has the advantages of a lower economic burden and a lower risk of dislocation after surgery [6]. Dislocation after bipolar hemiarthroplasty of the hip is a rare but 
devastating complication that has a great impact on patient quality of life $[7,8]$.

The specific risk factors for dislocation have not yet been identified but generally can be classified into patient factors, surgical factors, and morphological factors. Patient factors (history of neurological disease and weakness of abduction muscles), morphological factors (center-edge angle, femoral neck offset, and leg length discrepancy), and surgical factors (surgery approach, choice of prosthesis, and repair of the short external rotator tendons) were reported to play an important role in dislocation after bipolar hemiarthroplasty [9-12]. Adanir et al. reported measurements such as the center-edge angle and acetabular depth (which evaluated the shallowness of the acetabulum) were used to assess acetabular dysplasia [13], but the relationship between these measurements and dislocation after bipolar hemiarthroplasty for patients without acetabular dysplasia remained unclear. In the current study, we explored the morphological risk factors for dislocation after bipolar hemiarthroplasty.

\section{Materials and methods}

Between January 2011 and June 2017, 348 patients underwent bipolar hemiarthroplasty in our department because of femoral neck fractures. A total of 350 bipolar hemiarthroplasties were performed with 2 patients who underwent bilateral surgeries. All patients had a minimum follow-up of at least 1 year.

A nested case-control design was used to analyze the risk factors for dislocation. Dislocation occurred in 12 patients and 2 patients experienced more than 1 incident of dislocation. A control group of 60 patients without dislocation were selected from the remaining $336 \mathrm{pa}-$ tients, based on age, sex, and time of surgery (approximate ratio of 1:5 of case to control), as shown in Fig. 1. Seven patients with dislocation were treated through closed reduction while three patients were treated through open reduction. Two patients who had recurrent dislocations were treated through conversion to THA.

All bipolar hemiarthroplasties of the hip were performed following a posterolateral approach. Postoperative standard hip anteroposterior and lateral radiographs were obtained and rehabilitation training was guided by the same rehabilitation therapist team for all patients after surgery. All patients were instructed to avoid excessive hip adduction and internal rotation. Weight-bearing exercises started with the help of a walker or crutches during the first week and gradually increased to full weight-bearing within 4 weeks after surgery.

Patient data (age, sex, medical history including dementia, Parkinson's disease, lacunar infarction, and diabetes) were collected from patient medical records. Morphological factors, including center-edge angle,

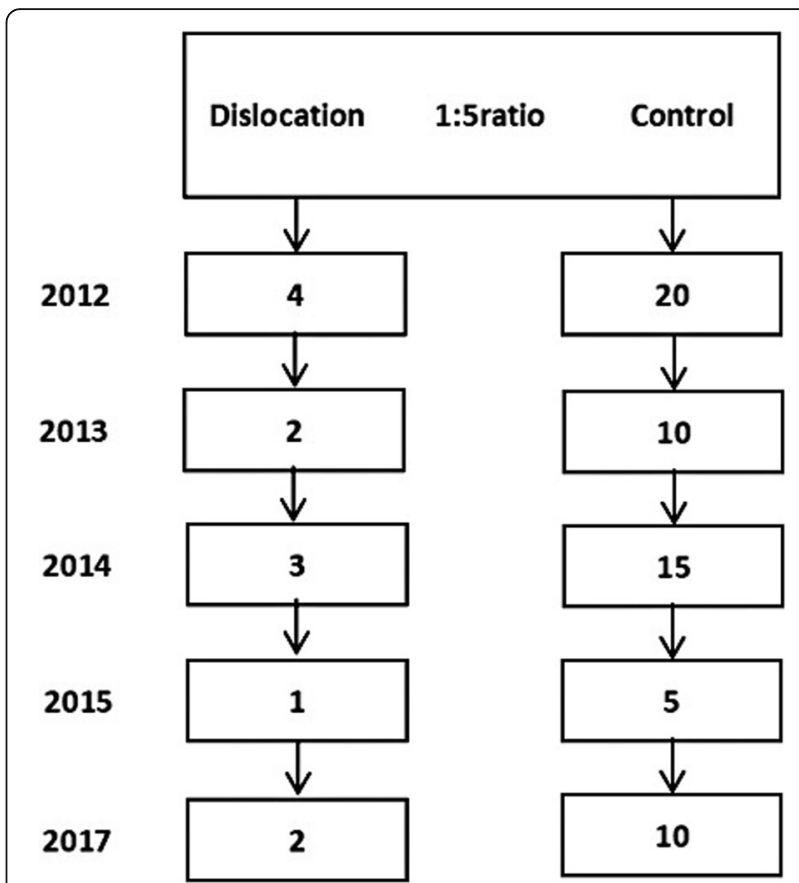

Fig. 1 The flowchart showed a nested case-control study with a ratio of 1:5 during the follow-up time from 2011 to 2017

abduction angle, acetabular depth and width, depth-towidth ratio, femoral neck offset, leg length discrepancy, and femoral head coverage ratio were measured from the hip anteroposterior radiographs after surgery.

The measurements of the center-edge angle (CE angle), abduction angle femoral neck offset, and leg length discrepancy are shown in Fig. 2 [14-16]. The measurement of the femoral head coverage ratio is shown in Fig. 3 [13]. The measurement of the acetabular width, depth, and depth to width ratio are shown in Fig. 4 [17].

\section{Statistical analysis}

\section{Statistical methods}

Categorical data were presented as counts and percentages. Continuous variables were presented as mean $\pm \mathrm{SD}$ or median (P25, P75) according to their distributions. The chi-square test was applied to test the equality of proportions. The Student $t$ test or Mann-Whitney $U$ test was used to test the difference between the two groups. A logistic regression analysis was performed to evaluate the hip measurements associated with dislocation. A receiver operating characteristic (ROC) curve was used to predict certain factors related to dislocation. In all the tests, a $P$ value of $<0.05$ was considered to indicate statistical significance. All the statistical analyses were performed using SPSS19.0 (SPSS Inc., Chicago, IL, USA). ROC curves were created using MEDCALC software (MedCalc Software, Mariakerke, Belgium). 


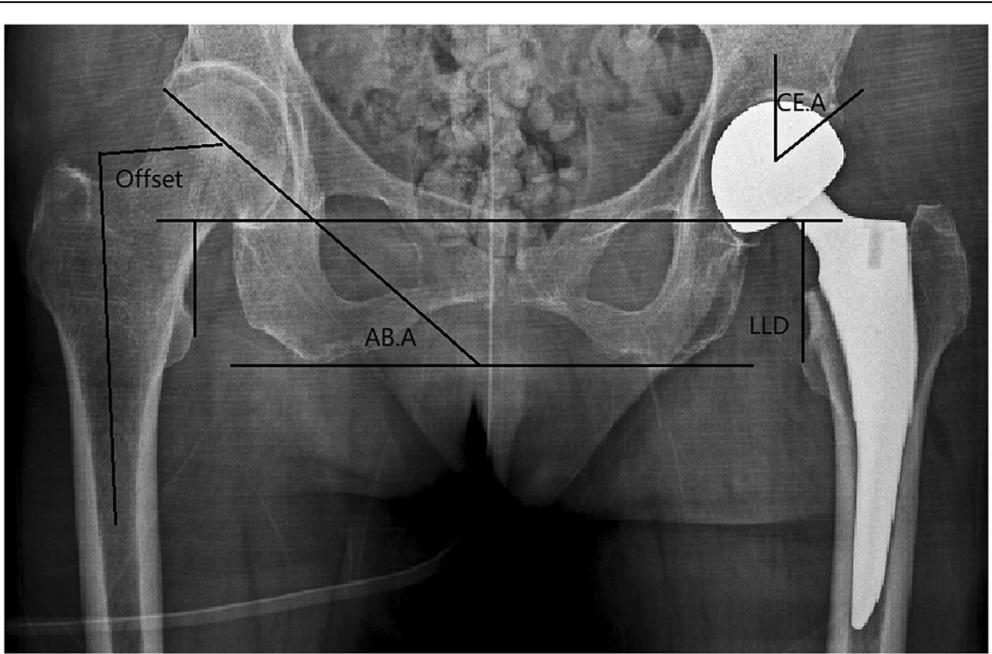

Fig. 2 Measurement of center-edge angle (CE.A), abduction angle (AB.A), leg length discrepancy (LLD), and femoral neck offset. (LLD is the difference in perpendicular distance between a line passing through the lower edge of the teardrop points to the corresponding tip of the lesser trochanter)

\section{Results}

The incidence of dislocation in the current study was $3.4 \%$ (12 of 348 patients), 1 male and 11 female patients with a mean age of 85 years. The value of the time from fracture to surgery and the time from surgery to dislocation followed the non-normal distribution, while all the other variables including the hip measurements followed the normal distribution according to the normal distribution test. All the hip measurements followed the equality of the variance between the two groups according to Levene's test $(P>0.10)$. The median time from bipolar hemiarthroplasty to the first incident of dislocation

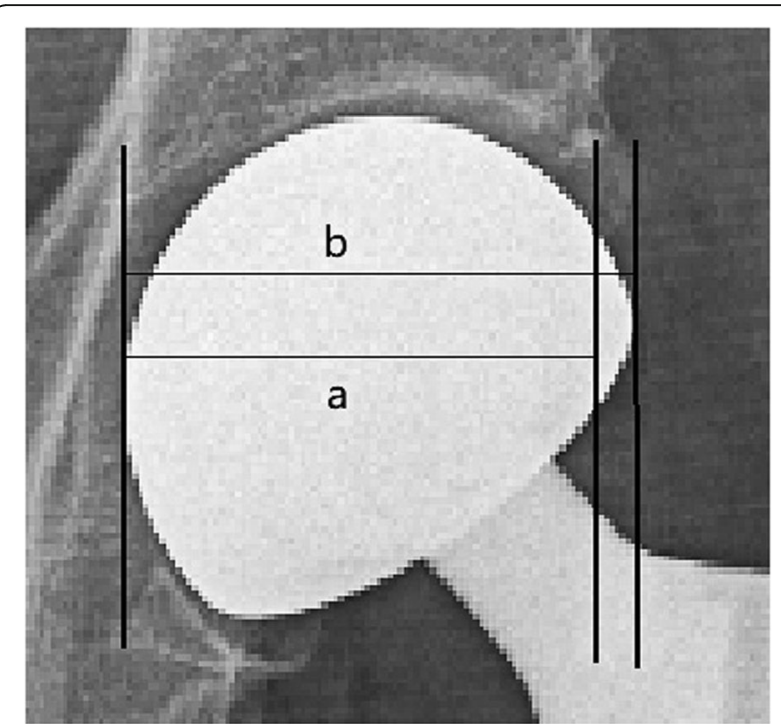

Fig. 3 Femoral head coverage ratio: ratio of the length between the innermost point of the femoral head and the outer corner of the acetabulum to the length of the femoral head (ratio of $a$ to $b$ ) was 36 days (range, 3-137 days). Eleven dislocations occurred within 2 months after surgery and 1 at 137 days. Eight patients suffered dislocations without trauma while four patients suffered dislocations because of a samelevel fall (Table 1).

No statistically significant difference existed between the two groups regarding age, sex, and medical history, including Parkinson's disease, dementia, lacunar infarction, and diabetes. The median time from fracture to surgery was 4 (range, 0.5-7) days in the dislocation group and 3 (range, 2-6) days in the control group, with no significant difference according to the MannWhitney $U$ test (Table 2).

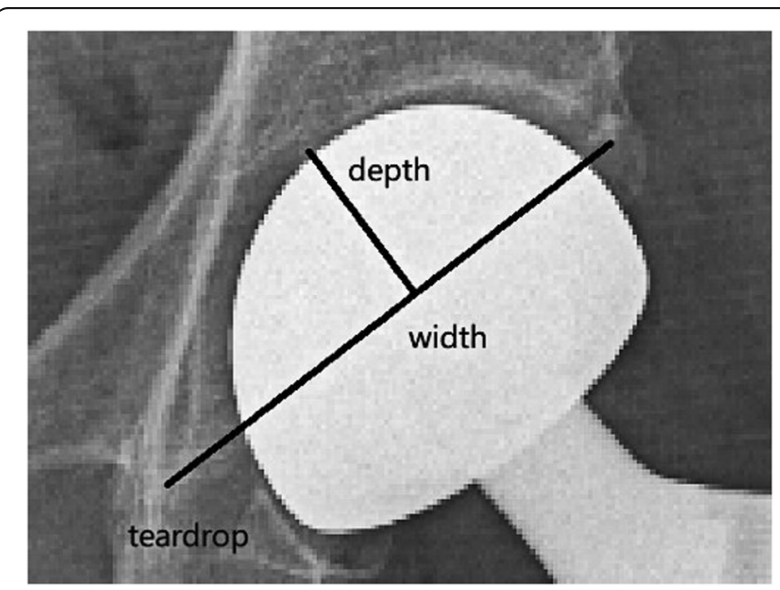

Fig. 4 Acetabular width: length of the line joining the lateral edge of the acetabulum to the pelvic teardrop. Acetabular depth: length of another line perpendicular to width line at the point of the greatest acetabular depth. Depth to width ratio: ratio of acetabular depth to width 
Table 1 Dislocation patient demographics including the sex, age, time from surgery to dislocation, cause of dislocation, treatment method, and medical history

\begin{tabular}{|c|c|c|c|c|c|c|}
\hline Patient number & Sex & Age (years) & Time from surgery to first dislocation (days) & Cause of dislocation & Treatment & Parkinson or dementia \\
\hline 1 & Female & 80 & 46 & Fall & Closed reduction & No \\
\hline 2 & Female & 87 & 15 & Atraumatic & Closed reduction & Dementia \\
\hline 3 & Female & 85 & 31 & Fall & Closed reduction & No \\
\hline 4 & Female & 75 & 15 & Atraumatic & Open reduction & No \\
\hline 5 & Female & 88 & 15 & Fall & Closed reduction & No \\
\hline 6 & Male & 83 & 23 & Fall & Open reduction & Parkinson \\
\hline 7 & Female & 89 & 54 & Atraumatic & Closed reduction & No \\
\hline 8 & Female & 84 & 14 & Atraumatic & Open reduction & No \\
\hline 9 & Female & 88 & 137 & Atraumatic & Closed reduction & No \\
\hline 10 & Female & 84 & 43 & Atraumatic & Closed reduction & No \\
\hline 11 & Female & 84 & 3 & Atraumatic & THA & Parkinson \\
\hline 12 & Female & 90 & 30 & Atraumatic & THA & No \\
\hline
\end{tabular}

Compared with an age-and-sex-matched control group, five hip measurements showed statistically significant differences in the dislocation group according to the Student $t$ test, as shown in Table 2. Patients in the dislocation group had a smaller $\mathrm{CE}$ angle $\left(38.9 \pm 5.9^{\circ}\right.$ vs. $\left.48.7 \pm 5.4^{\circ}, P<0.001\right)$, a greater abduction angle $(37.9 \pm$ 3.1 vs. $34.2 \pm 3.7^{\circ}, P=0.002$ ), a smaller acetabular depth $(17.58 \pm 2.19 \mathrm{~mm} \quad$ vs. $\quad 20.41 \pm 1.73 \mathrm{~mm}, \quad P<0.001), \quad$ a smaller depth-to-width ratio $(0.28 \pm 0.036$ vs. $0.32 \pm$
0.027, $P<0.001)$, and a smaller femoral head coverage ratio $(0.87 \pm 0.043$ vs. $0.92 \pm 0.047, P<0.001)$ (Table 2$)$. There were no statistically significant differences in other hip measurements according to the Student $t$ test, as shown in Table 2.

To investigate the five measurements ( $\mathrm{CE}$ angle, abduction angle, acetabular depth, depth-to-width ratio, and femoral head coverage ratio), which demonstrated significant differences in the dislocation group, we used

Table 2 Comparison of clinical data and acetabular measurements between dislocation and control group

\begin{tabular}{|c|c|c|c|}
\hline Characteristics & $\begin{array}{l}\text { Dislocation } \\
n=12\end{array}$ & $\begin{array}{l}\text { Control } \\
n=60\end{array}$ & $P$ value \\
\hline Age, years, mean $\pm S D$ & $84.8 \pm 4.2$ & $84.6 \pm 4.5$ & 0.897 \\
\hline \multicolumn{4}{|l|}{ Sex, $n(\%)$} \\
\hline Male & $1(8.3)$ & $5(8.3)$ & \\
\hline Female & 11(91.7) & 55(91.7) & \\
\hline \multicolumn{4}{|l|}{ Disease, $n(\%)$} \\
\hline Parkinson's & $2(16.7)$ & $4(6.7)$ & 0.567 \\
\hline Dementia & $1(8.3)$ & 2(3.3) & 0.426 \\
\hline Lacunar infarction & $5(41.7)$ & 23(38.3) & 1.000 \\
\hline Diabetes & $1(8.3)$ & 14(23.3) & 0.436 \\
\hline Time from fracture to surgery days, median (P25, P75) & $4(0.5,7)$ & $3(2.6)$ & 0.744 \\
\hline \multicolumn{4}{|l|}{ Measurements of hip, mean \pm SD } \\
\hline CE.A, & $38.9 \pm 5.9$ & $48.7 \pm 5.4$ & $<0.001$ \\
\hline AB. $A^{\circ}$ & $37.9 \pm 3.1$ & $34.2 \pm 3.7$ & 0.002 \\
\hline Width, mm & $64.16 \pm 3.03$ & $63.25 \pm 4.07$ & 0.520 \\
\hline Depth, mm & $17.58 \pm 2.19$ & $20.41 \pm 1.73$ & $<0.001$ \\
\hline Offset, mm & $31.88 \pm 8.09$ & $33.23 \pm 7.35$ & 0.569 \\
\hline LLD, mm & $2.77 \pm 8.43$ & $4.94 \pm 6.53$ & 0.322 \\
\hline D/W & $0.28 \pm 0.036$ & $0.32 \pm 0.027$ & $<0.001$ \\
\hline FC.R & $0.87 \pm 0.043$ & $0.92 \pm 0.047$ & $<0.001$ \\
\hline
\end{tabular}

CE.A center-edge angle, $A B . A$ abduction angle, $L L D$ leg length discrepancy, $D / W$ ratio of acetabular depth to width, $F C . R$ femoral head coverage ratio 
a multivariate logistic regression model. We formulated three models to investigate the link between the acetabular depth and depth-to-width ratio (Table 3). To compare their effects on the risk of dislocation, the values of the depth-to-width ratio, acetabular depth, and femoral head coverage ratio were standardized into $\mathrm{D} / \mathrm{W}-\mathrm{z}, \mathrm{D}-\mathrm{z}$, and FC.R-z using $z$-score normalization. A significant difference in the $\mathrm{CE}$ angle was observed in all three models. In model 1 , which involved all five measurements, the $\mathrm{CE}$ angle demonstrated the most significant difference (OR, 0.726; 95\%CI, 0.529-0.996; $P=0.047$ ). In model 2, where depth (D-z) was analyzed instead of depth-to-width ratio (D/W-z), a decreased CE angle (0R, $0.739 ; 95 \% \mathrm{CI}, 0.556,0.982 ; P=0.037)$ and a decreased depth (D-z) (OR, 0.146; 95\%CI, 0.025-0.860; $P=0.033$ ) were found to increase the risk of dislocation. In model 3 , where depth-to-width ratio $(\mathrm{D} / \mathrm{W}-\mathrm{z})$ was analyzed instead of depth $(\mathrm{D}-\mathrm{z}), \mathrm{D} / \mathrm{W}-\mathrm{z}$ showed the same trend as D-z (OR, 0.076; 95CI\%, 0.004-1.048; $P=0.084$ ), and additional effects were associated with a $P$ value approaching significance. The depth-to-width ratio (D/Wz) may have more predictive value than depth (D-z).

The abduction angle and femoral head coverage ratio both showed no significant difference in all three models. A smaller acetabular depth was associated with a higher risk of dislocation (OR, 0.146; 95\%CI, 0.025$0.860 ; P=0.033$ ) (model 2). However, when the depthto-width ratio was considered (model 1), it was not statistically significant (OR, 0.493; 95\%CI, 0.025-9.745; $P=$ 0.642). As shown in the ROC curve, predicting dislocation using the existence of a $\mathrm{CE}$ angle of no more than $45.4^{\circ}$ had a sensitivity of $100 \%$ and specificity of $80 \%$ (Fig. 5a). In addition, predicting dislocation using the existence of an acetabular depth of no more than 19.12 $\mathrm{mm}$ had a sensitivity of $83.3 \%$ and a specificity of $76.7 \%$ (Fig. 5b).

\section{Discussions}

It has been reported that compared with THA, bipolar hemiarthroplasty has a lower dislocation rate after surgery [6]. In theory, bipolar hemiarthroplasty involves an additional articulating joint within the head, thereby allowing movement to occur both at the prosthesis acetabular interface and within the prosthesis. In addition, the metallic shell has a large diameter, reducing the dislocation rate [18]. However, in the current study, dislocation still occurred at a rate of $3.4 \%$, which is in agreement with the published incidence of dislocation ranging from 1.1 to $5 \%[5,19,20]$. The factors contributing to dislocation are still controversial. Many factors have been reported to be associated with the occurrence of dislocation such as neuromuscular disease, surgical approach and the choice of prosthesis [9-12]. We performed the current study to investigate if morphological factors are associated with dislocation after bipolar hemiarthroplasty. We found that most of the dislocation patients had smaller acetabular coverage compared with the control group patients.

Radiographically, acetabular dysplasia is defined by either a $C E$ angle of $\leq 25^{\circ}$ (severe if $\leq 20^{\circ}$ ) or an acetabular depth of $<9 \mathrm{~mm}[21,22]$. In the current study, all the dislocation patients had a CE angle ranging from $29.6^{\circ}$ to $45.4^{\circ}$, and an acetabular depth ranging from 13.03 $\mathrm{mm}$ to $20.65 \mathrm{~mm}$, indicating that they did not display acetabular dysplasia. Although the patients were not considered to have acetabular dysplasia, the ROC curve showed that patients with a CE angle of $\leq 45.4^{\circ}$ or an acetabular depth of $\leq 19.12 \mathrm{~mm}$ were more likely to suffer dislocation after bipolar hemiarthroplasty. A Korean study also reported that people with a CE angle of $\leq 44^{\circ}$ were significantly more likely to suffer dislocation compared with those with a $\mathrm{CE}$ angle of $>44^{\circ}$ [10]. Here, we studied the ROC curve for the $\mathrm{CE}$ angle as well as for the acetabular depth.

In the current study, we found that a smaller CE angle was a major risk factor for dislocation after bipolar hemiarthroplasty (OR, 0.726; 95\%CI, 0.529-0.996; $P=$ 0.047 , model 1, Table 3). People with a smaller acetabular depth were more likely to suffer dislocation (OR, 0.46; 95\%CI, 0.025-0.860; $P=0.033$, model 2, Table 3). Acetabular depth can directly indicate the shallowness of the acetabulum and may affect dislocation. Compared with absolute acetabular depth, a smaller depth-to-width ratio may better describe the shallowness of the acetabulum in the case that a small acetabular width is also present. Although the depth-to-width ratio showed no

Table 3 Result of logistic regression of 5 measurements in 3 models

\begin{tabular}{|c|c|c|c|c|c|c|}
\hline \multirow[t]{2}{*}{ Variables } & \multicolumn{2}{|l|}{ Model 1} & \multicolumn{2}{|l|}{ Model 2} & \multicolumn{2}{|l|}{ Model 3} \\
\hline & $\overline{\mathrm{OR}(95 \% \mathrm{Cl})}$ & $P$ & $\overline{\mathrm{OR}(95 \% \mathrm{Cl})}$ & $P$ & $\overline{\mathrm{OR}(95 \% \mathrm{Cl})}$ & $P$ \\
\hline CE.A & $0.726(0.529,0.996)$ & 0.047 & $0.739(0.556,0.982)$ & 0.037 & $0.708(0.509,0.986)$ & 0.041 \\
\hline AB.A & $0.876(0.626,1.227)$ & 0.442 & $0.918(0.688,1.226)$ & 0.564 & $0.851(0.614,1.179)$ & 0.331 \\
\hline FC.R-Z & $0.874(0.234,3.267)$ & 0.841 & $0.764(0.233,2.502)$ & 0.657 & $0.859(0.244,3.028)$ & 0.813 \\
\hline$D-z$ & $0.493(0.025,9.745)$ & 0.642 & $0.146(0.025,0.860)$ & 0.033 & & \\
\hline$D / W-z$ & $0.170(0.002,12.106)$ & 0.416 & & & $0.076(0.004,1.408)$ & 0.084 \\
\hline
\end{tabular}

CE.A center-edge angle, $A B . A$ abduction angle, $F C . R-z$ femoral head coverage ratio-z, $D-z$ acetabular depth-z, $D / W-z$ depth-to-width ratio-z 

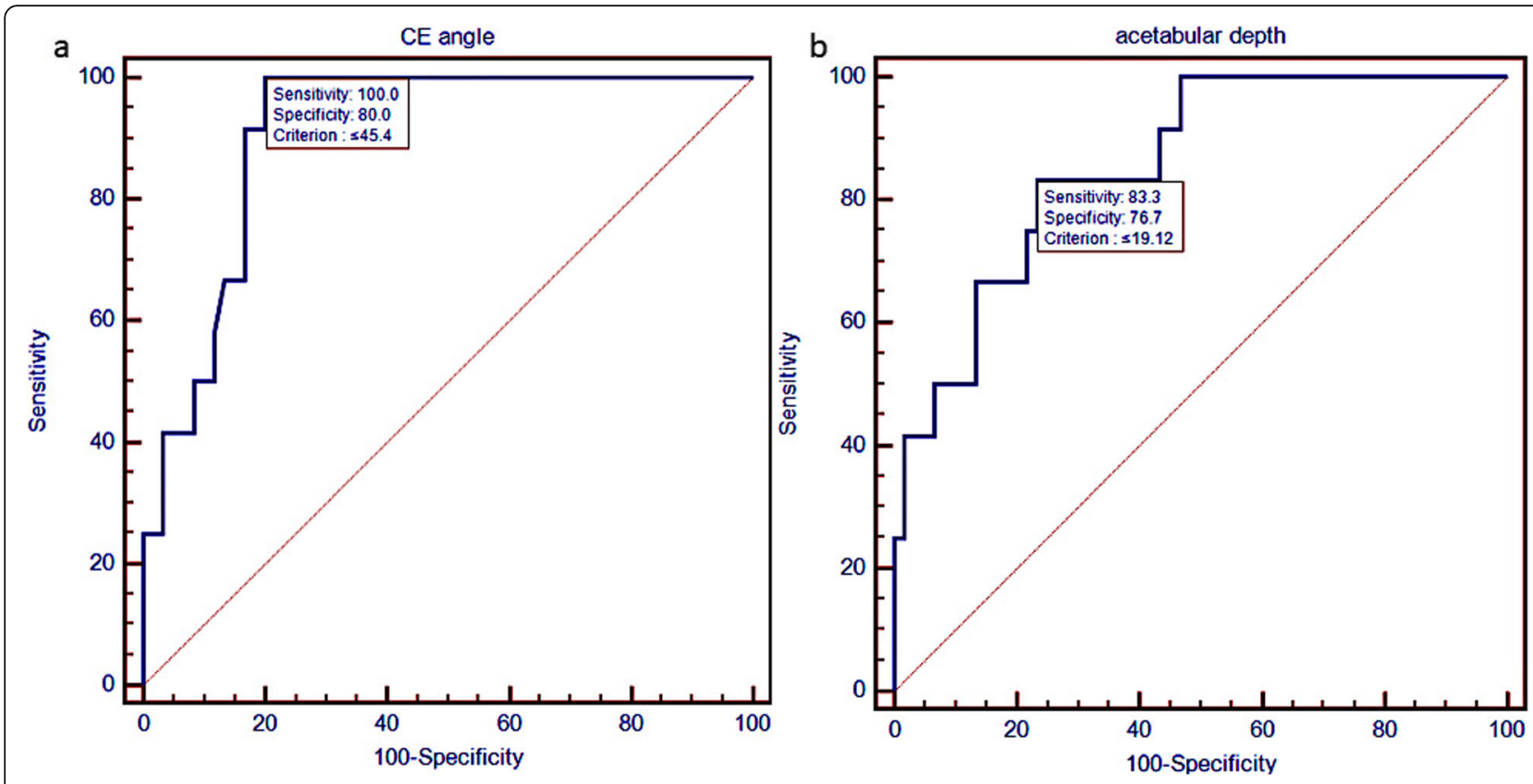

Fig. 5 ROC curves of $\mathbf{a} C E$ angle and $\mathbf{b}$ acetabular depth as criterion for dislocation

significant difference in all the models, it should be taken into consideration when the acetabulum is measured. Compared with acetabular depth, the depth-towidth ratio may reduce individual variation and better evaluate the degree of shallowness of the acetabulum (Table 3).

Bipolar hemiarthroplasty does not change the morphology of the acetabular side, especially when patients have shallower acetabular measurements such as a smaller CE angle and a smaller acetabular depth, which predisposes them to dislocation. Patients with a shallower acetabulum may be prone to dislocation after bipolar hemiarthroplasty. Compared with bipolar hemiarthroplasty, THA has the advantage of adjusting the acetabular side. Cobb et al. found that when an elevated liner of the acetabulum was used in THA, the stability of the hip after THA was improved and a lower dislocation risk was found [23]. Nakashima $Y$ et al. reported that cement-free stem anteversion varied widely and a combined anteversion technique is useful to reduce the incidence of dislocation in cementfree THA [24]. THA has the advantages of correcting the shallowness of the acetabulum directly by setting an acetabular cup and adjusting the combined anteversion by controlling both femoral and acetabular anteversion while bipolar hemiarthroplasty can only adjust the anteversion of the femoral side.

For recurrent dislocation after bipolar hemiarthroplasty, conversion to THA is usually used. Sierra et al. suggested that for dislocation patients with additional contributing factors such as a shallow acetabulum socket, open reduction is needed, with or without component revision including conversion to THA [20]. In a study performed by Encoson et al., 1 of 720 patients had recurrent dislocation after bipolar hemiarthroplasty because of a shallow acetabular socket and was finally treated by converting to THA [9]. In the current study, two patients suffered from recurrent dislocation. They had indications of a comparatively shallow acetabulum (CE angle of $30.3^{\circ}$ and $31^{\circ}$, acetabular depth of $15.31 \mathrm{~mm}$ and $13.03 \mathrm{~mm}$ ). Both of the patients were treated with a surgical conversion to THA and did not suffer from subsequent dislocations. THA has the advantage of providing better acetabulum coverage to correct acetabular shallowness.

There are some limitations to the current study. The sample size was relatively small and the incidence of dislocation was $3.4 \%$. A nested case-control is often used when the outcome is rare or when the interest of exposure difficult to obtain. In the current study, we performed a 1 : 5 ratio nested case-to control study. For each dislocation patient, we matched five control patients in terms of age, sex, and time of surgery to eliminate several confounding factors and increase the reliability of the study.

\section{Conclusion}

In conclusion, the current study suggests that a smaller $\mathrm{CE}$ angle is a risk factor for dislocation after bipolar hemiarthroplasty. There was a trend for people with a smaller acetabular depth or depth-to-width ratio to suffer from postoperative dislocation. A bipolar hemiarthroplasty should be carefully considered when the acetabulum tends to be shallow and a total hip replacement should be performed if necessary. 


\section{Abbreviations}

CE: Center-edge angle; D/W: Depth-to-width ratio; FC.R: Femoral head coverage ratio; ROC: Receiver operating characteristic; THA: Total hip arthroplasty

\section{Acknowledgements \\ None.}

\section{Authors' contributions}

YQZ, ZJY, and PS were co-first authors. CZ and YY were both corresponding authors. ZJY, CZ, and YY organized, conceived, and designed the study. YQZ, CZW, and JYL collected clinical data and carried out the study. YQZ and PS performed statistical analysis and comprehensively interpreted the data. YQZ wrote the manuscript. ZJY, PS, CZ, and YY revised and edited the manuscript. All authors reviewed the results and approved the final version of the manuscript.

\section{Funding}

The study received no external funding.

\section{Availability of data and materials}

The datasets used and/or analyzed during the current study are available from the corresponding author on reasonable request.

\section{Ethics approval and consent to participate}

This study was approved by Zhongshan Hospital, Fudan University, Shanghai, China, and was performed in accordance with the standards of the National Research Council. All patients provided signed informed consent to allow their clinical and radiologic data to be used for research programs.

\section{Consent for publication}

Not applicable.

\section{Competing interests}

The authors declare that they have no competing interests.

\section{Author details}

'Department of Orthopedic Surgery, Zhongshan Hospital, Fudan University, 180 Fenglin Road, Shanghai 200032, China. ${ }^{2}$ Children's Hospital of Fudan University, 399 Wanyuan Road, Shanghai 201102, China.

Received: 11 June 2019 Accepted: 10 October 2019

Published online: 28 November 2019

\section{References}

1. Brozek W, Reichardt B, Kimberger O, Zwerina J, Dimai HP, Kritsch D, et al. Mortality after hip fracture in Austria 2008-2011. Calcif Tissue Int. 2014;95(3): 257-66.

2. Klop C, Welsing PM, Cooper C, Harvey NC, Elders PJ, Bijlsma JW, et al. Mortality in British hip fracture patients, 2000-2010: a population-based retrospective cohort study. Bone. 2014;66:171-7.

3. Cooper C, Campion G, Melton LJ 3rd. Hip fractures in the elderly: a worldwide projection. Osteoporos Int. 1992;2(6):285-9.

4. Roberts KC, Brox WT. From evidence to application: AAOS clinical practice guideline on management of hip fractures in the elderly. J Orthop Trauma. 2015;29(3):119-20

5. Haidukewych GJ, Israel TA, Berry DJ. Long-term survivorship of cemented bipolar hemiarthroplasty for fracture of the femoral neck. Clin Orthop Relat Res. 2002:403:118-26.

6. Lee BP, Berry DJ, Harmsen WS, Sim FH. Total hip arthroplasty for the treatment of an acute fracture of the femoral neck: long-term results. J Bone Joint Surg Am. 1998;80(1):70-5.

7. Enocson A, Pettersson H, Ponzer S, Tornkvist H, Dalen N, Tidermark J. Quality of life after dislocation of hip arthroplasty: a prospective cohort study on 319 patients with femoral neck fractures with a one-year followup. Qual Life Res. 2009:18(9):1177-84.

8. Petersen MB, Jorgensen $H L$, Hansen K, Duus BR. Factors affecting postoperative mortality of patients with displaced femoral neck fracture. Injury. 2006;37(8):705-11.

9. Enocson A, Tidermark J, Tornkvist $H$, Lapidus $U$. Dislocation of hemiarthroplasty after femoral neck fracture: better outcome after the anterolateral approach in a prospective cohort study on 739 consecutive hips. Acta Orthop. 2008;79(2):211-7.

10. Kim Y, Kim JK, Joo IH, Hwang KT, Kim YH. Risk factors associated with dislocation after bipolar Hemiarthroplasty in elderly patients with femoral neck fracture. Hip \& pelvis. 2016;28(2):104-11.

11. Li L, Ren J, Liu J, Wang H, Sang Q, Liu Z, et al. What are the risk factors for dislocation of hip bipolar Hemiarthroplasty through the anterolateral approach? A nested case-control study. Clin Orthop Relat Res. 2016;474(12): 2622-9.

12. Madanat R, Makinen TJ, Ovaska MT, Soiva M, Vahlberg T, Haapala J. Dislocation of hip hemiarthroplasty following posterolateral surgical approach: a nested case-control study. Int Orthop. 2012;36(5):935-40.

13. Adanir O, Zorer G. Comparison of four parameters to assess acetabular dysplasia and acetabular dysplasia rates in primary hip osteoarthritis patients: A study in Turkish population. J Orthop Surg (Hong Kong). 2018; 26(2):2309499018768032.

14. Mukka S, Lindqvist J, Peyda S, Broden C, Mahmood S, Hassany H, et al. Dislocation of bipolar hip hemiarthroplasty through a postero-lateral approach for femoral neck fractures: a cohort study. Int Orthop. 2015;39(7): $1277-82$.

15. Wiberg G. Shelf operation in congenital dysplasia of the acetabulum and in subluxation and dislocation of the hip. J Bone Joint Surg Am. 1953;35-a(1): 65-80.

16. Zeng Y, Wang Y, Zhu Z, Tang T, Dai K, Qiu S. Differences in acetabular morphology related to side and sex in a Chinese population. J Anat. 2012; 220(3):256-62.

17. Heyman $\mathrm{CH}$, Herndon $\mathrm{CH}$. Legg-Perthes disease; a method for the measurement of the roentgenographic result. J Bone Joint Surg Am. 1950; $32 \mathrm{a}(4): 767-78$.

18. Shoji T, Yasunaga Y, Yamasaki T, Izumi S, Hachisuka S, Ochi M. Low femoral antetorsion as a risk factor for bony impingement after bipolar hemiarthroplasty. J Orthop Surg Res. 2015;10:105.

19. Barnes CL, Berry DJ, Sledge CB. Dislocation after bipolar hemiarthroplasty of the hip. J Arthroplast. 1995;10(5):667-9.

20. Sierra RJ, Schleck CD, Cabanela ME. Dislocation of bipolar hemiarthroplasty: rate, contributing factors, and outcome. Clin Orthop Relat Res. 2006;442: 230-8.

21. Han CD, Yoo JH, Lee WS, Choe WS. Radiographic parameters of acetabulum for dysplasia in Korean adults. Yonsei Med J. 1998;39(5):404-8.

22. Yoshimura N, Campbell L, Hashimoto T, Kinoshita H, Okayasu T, Wilman C, et al. Acetabular dysplasia and hip osteoarthritis in Britain and Japan. Br J Rheumatol. 1998:37(11):1193-7.

23. Cobb TK, Morrey BF, Ilstrup DM. The elevated-rim acetabular liner in total hip arthroplasty: relationship to postoperative dislocation. J Bone Joint Surg Am. 1996;78(1):80-6

24. Nakashima Y, Hirata M, Akiyama M, Itokawa T, Yamamoto T, Motomura G, et al. Combined anteversion technique reduced the dislocation in cementless total hip arthroplasty. Int Orthop. 2014;38(1):27-32.

\section{Publisher's Note}

Springer Nature remains neutral with regard to jurisdictional claims in published maps and institutional affiliations.

Ready to submit your research? Choose BMC and benefit from:

- fast, convenient online submission

- thorough peer review by experienced researchers in your field

- rapid publication on acceptance

- support for research data, including large and complex data types

- gold Open Access which fosters wider collaboration and increased citations

- maximum visibility for your research: over $100 \mathrm{M}$ website views per year

At $\mathrm{BMC}$, research is always in progress.

Learn more biomedcentral.com/submissions 